\title{
MASTER
}

SAND78-1188

Unlimited Releces

Neutron Generator Instrumentation at the Department 2350 Neutron Generator Test Facility

Theodore C. Bryent, Gary R. Mowner 


\title{
MASTER
}

SANDT8-11:B

Jistribution Category UC-37

Printed June 1979

IEUTRON GELERATUR IRSTRUMEWTATION AT THE

DEPARTMENT 2350 MEUTRON GENERATOR TEST FACILITY

Theodore C. Bryant

Gary R. Mowrer

Generator Development Division

Sandia Laboratories

Albuquerque, New Mexico 87185

\begin{abstract}
The computer and waveform digltizing capability at the test faclitity has allowed several changes in the techniques used to test neutron generators. These changes include methods used to calibrace the instrumentation and changes in the operation of the test facility. These changes have increased the effictency of the test facility as well as increasing both timing and amplitude accuracy of neutron generator waveforms.
\end{abstract}

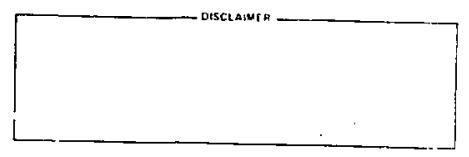




\section{TABLE OF CONTENTS}

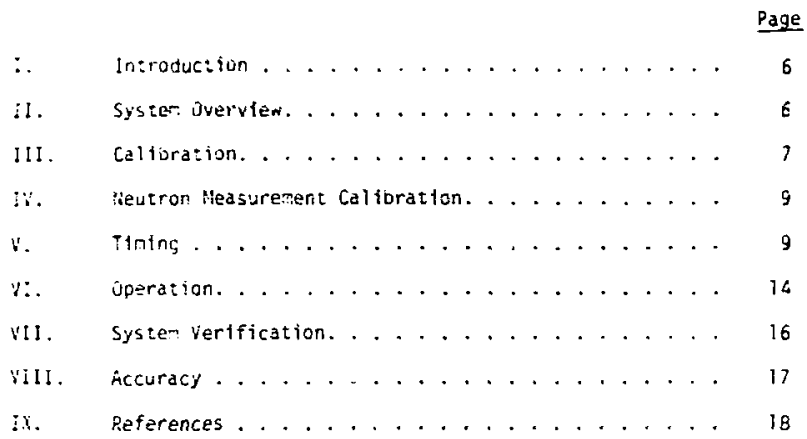


Figure No.

Page

\begin{tabular}{|c|c|c|c|c|c|}
\hline 1 & 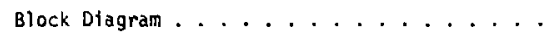 & . & . & $\cdot$ & \\
\hline 2 & Calibrator Photo. . . . . . . . . & , . & & - & \\
\hline 3 & Typtcal Setup Timing Block Diagram. . . . . & . & & • & \\
\hline 4 & Detonator Current and Bridgewire Burst Waveform & . . & & 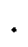 & ${ }^{\circ}$ \\
\hline 5 & FS Trig and FS Delay Time Interval Meters.. & . & & & \\
\hline 6 & Simplified TCORR Black Diagram. . . . . & . & & . & \\
\hline 7 & 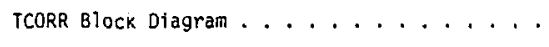 & . & & $\bullet$ & \\
\hline 8 & Digitizer Hardware Block Diagram. . . . . . &,${ }^{\circ}$ & & & \\
\hline 9 & Transformer Assembly . . . . . . . . & . & & . & \\
\hline & 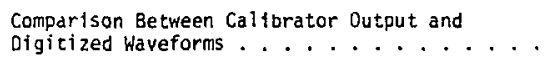 & & & & \\
\hline
\end{tabular}




\section{INTROJUCTIUN}

The digitizing of neutron generator waveforins has led to increased computer control of the tes: facility which has caused changes in the tecliniques and instrumentation used to test neutron yenerators. Digitized waveforms are now the prlmary method of recording data from the testing of neutron generators. Oscilloscopes are used to back up the digltizing system when testing explosively actlvated neutron generators and for fmmediate access to tne data after the test. Oscilloscopes are not used in the testing of electronic neutron generators.

io fully utitize the computer, majar changus in the methods used to determine timing of the various nejtron generator wateforms and to calibrite the digitizers have been irapientented. Since these changes affect the data used by neutron generators engineers. it is essential that the test facility Instrimentation as it now exfsts be fully docuinented. The basic digitjzing systelr will not be covered here since it is described in other documentation. $(1,2)$

\section{SYYSTEF OVERVIEW}

Figure 1 is a block diagram of the new method of instrumentation.

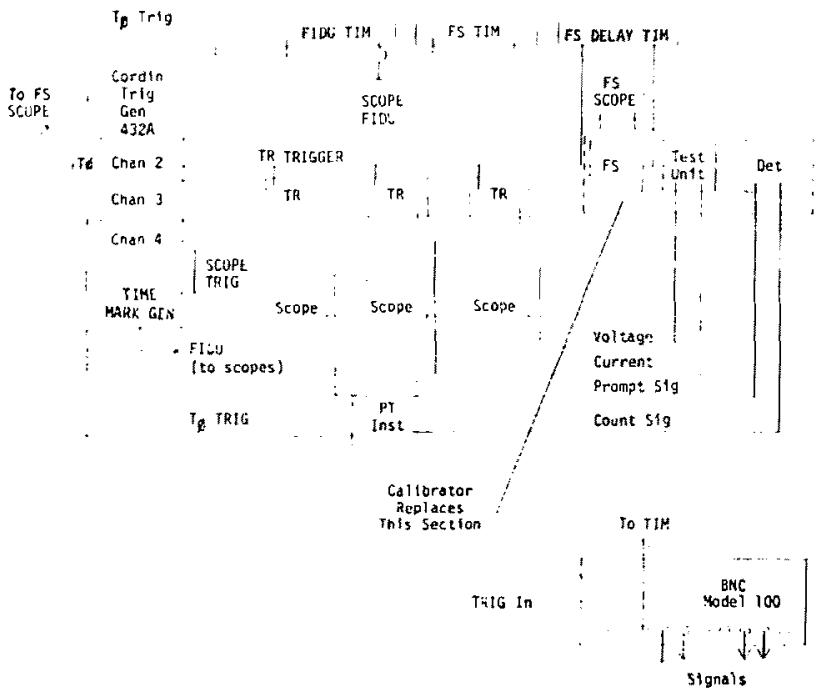

Flaure?. Block Dlagram 
A major change to the system is that the bridgewire burst (BWB) waveform is not used for triggering with the new system, although BWB Is still the timing reference. ihis change means that the initlal trigger $\left(T_{D}\right)$ and BWB are not aligned in time.

A calibrated multichannel signal generator called "the callbrator." is used to 51 mulate the waveforms from the neutron generator to be tested. This signal generator is callorated by Sandia Standards, and various channels are used to provide waveforms stmilar to the waveforms from any explosive or electronic neutron generator.

a Cordin Model 432 delay generator is used to trigger the oscilloscopes, translent recorders, PT instruments, and the firing set (explosive neutron generators) or trigger signal (electronic neutron generators).

Timing corrections (TCORR) for non-real dffferences between trigger and signal arrivals at the transient recorders are calculated by the computer using an interfaced Eldarado Model 796 time Interval counter. The TCORR for each transient recorder, along witn the time interval between the input trigger to the firing set and the neutron generator detonator bridgewire burst or trigger are used to calculate the actual time of the digitized waveforms.

Trigger levels throuahout the system have dropped from $300 \mathrm{~V}$ to $28 \mathrm{~V}$ or less. A new firing set (U833T) was purchased from Monsanto Research Corporation to provide consistency among Monsanto, Genera? Flectric Company Fieutron Devices Department, and Sandia Laboratories. This firing set is compatible with the lower trigger levels now in use.

Details of the calibrator and timing, as well as some evaluation of the system, are given in the following sections of this report.

\section{I1I. CALIBRATION}

Two methods are usec for calibration of the translent recorders. A dc calibrator applier a known voltage to the transient recorder input. (3) This dc input is digftized and a calibration factor calculated by the BASIC program. This method is used to eliminate the effects of any drift of the transient recorder circuitry and is done before each operation of the transient recorder. In addition to this method, before each neutron generator test, a set of waveforms whicin simulate the neutron generator to be tes.ed are generated by the calibrator, which is physically located in place of the neutron generator. The BASIC program checks the digltized amplitude of each waveform and calculates a calibration factor for each transient recorder based on the known amplitude of the signal at the calibrator and the amplitude of the digitized waveform. The tralling slope of the flat-topped waveform from the calibrator may also be used to check the input amplifier crossover of the Blomation Model 8100 . The calibrator is calibrated and certifted by the Sandia Standards Department.

There is a BASIC program used to check the transient recorders on an occasional basis. It uses a $1 \mathrm{MHz}$ sine wave input and checks for the fit of the digitized waveform to a I $\mathrm{MHz}$ sine wave.

Figure 2 is a photograph of the calibrator, connected to the transformer buard. The calibrator corsists of modified Berkley Nucieonics Corporation signal generators and an unmodified delay generator. The calibrator 15 arbitrarlly called the BNC Model 100 and provides 10 channeis of pulse output delayed in increments of 0.1 us.

A BNC Model 7020 is used to generate the required delay; two Model 8016-4s provide four positive $50 \mathrm{~V}$ pulses; two Model 8016-5s provide four positive or negative switchselectabie $50 \mathrm{~V}$ pulses; and a Model g016-6 provides two positive or negative 5 or $10 \mathrm{~V}$ pulses. These units are mounted in a Mode? TB-4 chassis which alsa provides power. 


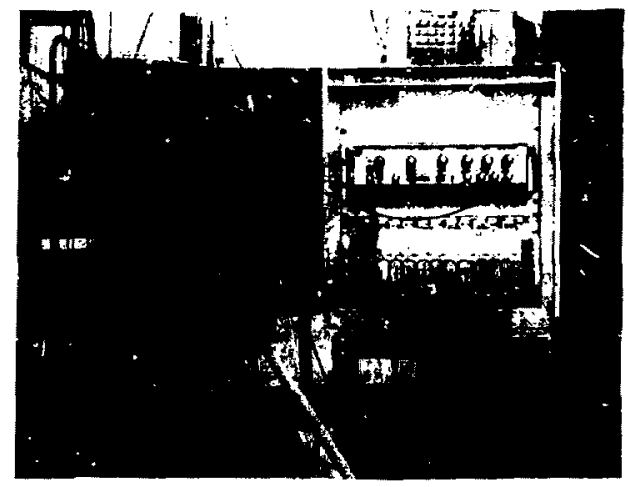

Figure 2. Calibrator

The 50 v chanuels were modified at the factory by clamping the outputs with zener diodes to $1 \mathrm{mprove}$ reproducitility. The calibrator was further modified at the test facility by putting $50 \mathrm{a}$ resistors in series with the $50 \mathrm{~V}$ outputs to provide shortcircult outputs of approximately $1 \mathrm{~A}$.

Before each explosive neutron generator test series, all instrumentation is calibrated and TCORR determined for digitized data by using the calibrator. Wth all instrumentation connected, a set of waveforms with known amplitudes is generated by the callbrator (i.e., currents through current transformers, $10 \mathrm{y}$ for the pick-up plate (PUP) measurement, and a dumny neutron waveform). Each $T R$ determines the apparent time delay of 1 ts signal and then corrects this time ty the interfaced time interval counter reading. This produces a TCORR for each TR.

Ac the same time, each $i R$ digftizes and measures the amplitude of its waveform, Sandia Standards lists the current output of each current channel with an accuracy of $\pm 5:$ and the output of each voltage channel with an accuracy of $\pm 4 \%$. These values are stored on the computer's RK.05 disk file which Is accessible by the BASIC program. since the exact value of the calibration waveform is known, any inaccuractes in the current transformers, attenuators, or cable losses are eliminated by the compute: since it compares the amplitude of the waveform from the callbrator as read by a transient recorder with the value from the disk and adjusts the sensitivity accordingly. 


\section{NEUTRON MEASUREMENT CALIBRATION}

The neutron calibration is based on the barlum bolt count as read by the scaler. The neutron measurement is determined by the scaler reading and the probe factor.

Sensitivity for the neutron prompt waveform is determined by the ratto of the scaler reading, as read by the computer using the scaler interface, to the integral of the neutron waveform, as calculated by the computer using the digitized waveform from the transient recorder.

The neutron prompt waveform is set to a canvenient amplitude by selecting appropriate attenuator and transient recorder ranges. The rate level is not set on the uscilloscope, but a voltage equivalent of the rate level is recorded.

Although calculating the neutron sensitivity on a shot-to-shot basis eliminates any errors caused by promp: neutron detector drift, another problem is generated. If a waveform goes off-scale and is clipped, the sensitivity is in error by the ratio of the integral of the clipped area and the normal integral. To avoid clipping and stlli use at least 75\% of the available digitizing window, two digitizers are used with the dual-probe neutron detectors, when possible. A software check is made to see if the more sensitive transient recorder is off-scale. If it is off-scale, the neutron prompt waveform is taken from the transient recorder which is set to the iess sensitive scaie. On neutron generators which have too many waveforms to allow two tran.ient recorders to be dedicated to the neutron waveform, coriservative scales are selected and lower resolution accepted.

An additional advantage of the system described in this section is that attenuators for the neutron waveform transient recorders may be added or subtracted with no changes in program input since the calibration is done on each waveform.

\section{TIMING}

Functional testing of neutron generators determines not only the neutron output, but the time of the neutron pulse as well. However, in order to measure the time of a neutron pulse. it must be referenced to some initial time. On electronic generators, this reference time is the initial trigger to the neutron generator. On explosive generators, the usual reference timing point is the detonator bridgewire burst. The time interva? until neutron output, etc., can then be measured from the initiai time reference.

The measurement of timing information on explosive neutron generators presents some unisual difficulties not present with electronic types. Ideal1y, all instrumentation would be triggered at bridgewire burst tfme. However, the bridgewire burst waveform is not necessarily an ideal trigger waveform. In addition, this event occurs remotely, and a time delay is introduced bringing the sfinal to, and triggering, numerous delay generators for all the instruments used on the test. Also, should the bridgewire burst waveform be lost or of insufficient amplitude to trigger the delay generator, ali information regarding the test would be lost. The one-time operation of the explosive generator makes it imperative thw al 1 instruments be triggered and ready to accept data. These and other considerations produced the system showm in block diagram form in Figare 3. For clartity, only the neutron measurement is shown. 


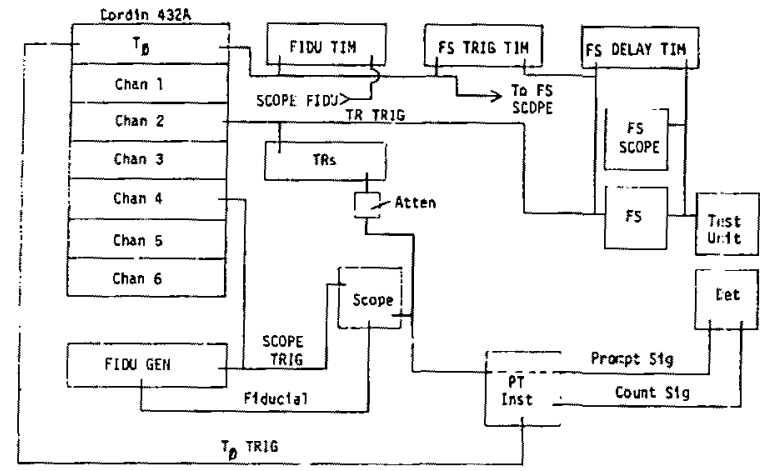

Figure 3. Typical Timing Setup, Block Diogram

The heart of this timing system is the cordin $432 \mathrm{~A}$ six-channel delay generator. The $432 A$ provides six independent delays varlable by front panel swltcres from 0.10 to 999.99 us in $10 \mathrm{~ns}$ increments referenced to the zero delay output ( $T_{0}$ ). The manufacturer's stated accuracy is $\pm 20 \mathrm{~ns} \pm 0.1 \%$ of the delay setting. However, the jitter is quoted at \pm 5 ns referenced to the zero delay output. While these figures seem to have the accuracy required, other delays and variattons make it more convenient to monitor important delays with time interval meters.

An external trigger applied to the Cordin $432 \mathrm{~A}$ starts the following sequence of events (Figure 3 ). The zero delay output ( $T_{g}$ ) from the Cordin starts the firing set trigger time interval meter (FS TRIG TIM), the firing set monttar scope, the scope fiducial time interval meter (FIDU TIM), and the production testing (PT) equipment.

The Channel 2 delayed trigger from the Cordin (nomally set for a delay of $1.00 \mathrm{us}$ ) triggers the transient recorders (TRs) and the firing set. The TRs are triggered somewhat earlier than the firing set due to cable transit time to the test area. The Channel 2 delayed trigger appifed to the firing set is used to stop the firing set trigger time interval meter (FS TRIG TIII) and to start the firing set delay time interval meter (FS OELAY TIM) which is interfaced to the computer. This trigger is also monitored by the firing set monitor scope to confirm the delay read by the FS DELAY TIM.

Bridgewire burst as seen at the firing set output is used to stop the FS DELAY TIM. The start and stop cable lengths to this time interval meter are equal to cancel their time delays. The bridgewire burst waveform (FIgure 4) is monitored by the firing set monicor scope to ensure that the FS DELAY TIM is stopping on the proper portion of the waveforn. The bottom trace in Figure 4 is an added waveform. The first portion of 


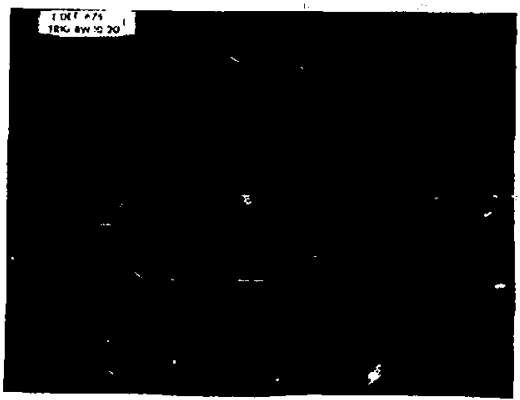

Figure 4. Detonator Current and Bridgewire Burst Waveform

the trace is the trigger applied to the firing set, while the second half shows the bridgewire burst waveform added. The time of interest is the time from the trigger (negative-going step) until the spike produced when the bridgewire actualiy bursts. Care should be taken during set-up to verify that the FS DELAY TIM does not read the time to the first step on the bridgewire burst waveform instead of BWB. The step on the waveform indicates the firing set dump time, but a short time is required for the detonator current to reach a sufficient level to cause burst of the bridgewire.

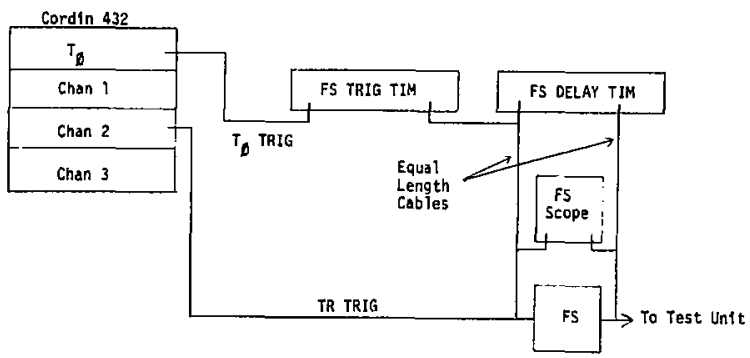

Figure 5. FS TRIG \& FS DELAY Time Interval Meters 
Figure 5 shows the firing set delay time interval meter (FS DELAY TIM) in s1mplified form. The FS DELAY TIM provides accurate tfming information on the internal delay of the firing set. The time read by the FS DELAY TIM is used to correct the digitized timing information to bridgewfre burst reference.

The Channel 4 delayed trigger (Figure 3) from the cordin is used to trigger most of the scopes that are used during testing. This delay may be set as required to produce a scope sweep that covers the desired time interval. In addition to triggering the scopes, it triggers a pulse generator that provides a scope trace blanking pulse for timinq comparison about 2 is after the scope sweep begins. The time interval from the cordin ze:0 time delay reference to the t1me mark is measured by the SCOPE FIDU TIM.

Tile scope fiducial time and any timing information determined by the PT instruments is referenced to the cordin zero time output. However, the difference between Cordin zero time output and bridgewire burst has been measured by the FS TRIG TIM and the FS DELAY TIM (Figure 5). The sum of these two time measurements is used to correct the scope fiducia] time and the PT timing information to the bridgewire burst reference.

In order to improve the timing accuracy of the digftlzed data, a time correction (TCORR) has been applied to the digltized data timing information.

The need for TCORR can be seen by referring to Ftgure 6 . The block dlagram portion of Figure 6 shows the same trigger used for the transfent recorder and the firing set. The transient recorder portion of the timing diagram shows that the trigger signal to the $T R$ and the firing set, if parched directly to the TR signal Iine, would appear as a signal at time "C" later $(A+B)$. However, this apparent "signal" is actually the firling set trigger as seen by the transient recorder. TIme " $C$ " is measured by the TR and referred to as TCORR. In effect, by subtracting $t$ fme " $\mathrm{C}$ " from a delay measured by the TR, the TR trlgger and the firing set trigger now occur simultaneously.
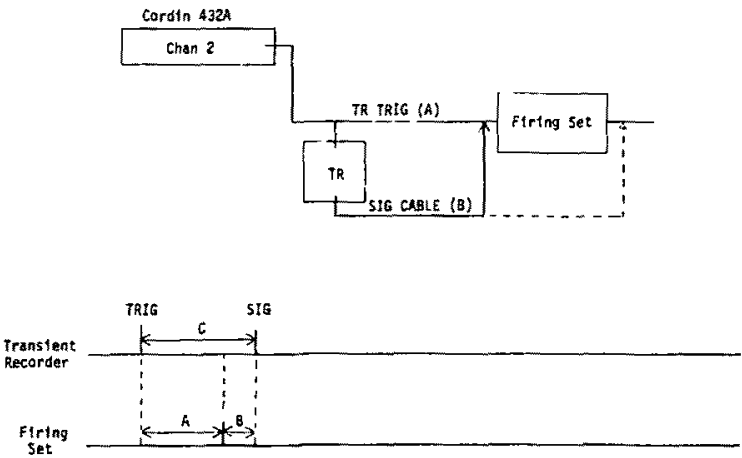

Figure 6. Simplified TCORR Block Diagram 
In actual practice when determining TCORR for as many as S1x TRs, it is riot practical to patch the trigger jine to each sfgnail line and repect the TCORR operation until zime " $C$ " has been determined for each $T R$ in use. Instead, the calibracor described in Section III of this report is used to determine TCORR for all TRs in use for a particular test.

One difficulty that arises when determining TCORR 15 the internal delay of the Model 100 calibrator. The internal delay of the Mode1 10015 repeatable when referenced to its own zero time output. However, from trigger in to pulse out, the varfations are great enough to require that these variations be measured with a time interval meter.

"n order to include the Model 100 calibrator varlability in TCORR measurement, the FS DELAY TIM is used to fisasure the time delay from trigger in to the Model 100 untll pulse out. Figure 7 . This time is subtracted by the computer from the apparent signat delay ( $t$ ime "C") and the actual TCORR determined. Variations in the delay of the Mode? 100 are accounted for in this manner. Since the pulse generator delay is equal for all channels, this time is subtracted by the computer from the apparent signal delay measured by each TR. The remaining apparent signal delay is then due to differences in trigger and signal cables and represents the actual TCORR for each TR.
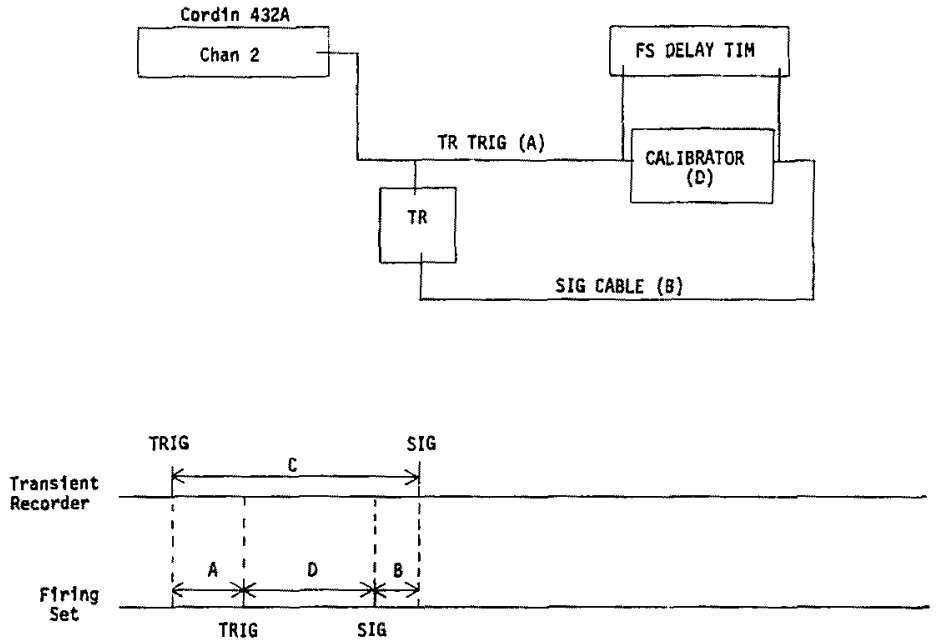

Figure 7. iCORR Block Dlagram 


\section{OPERATION}

Testing of efther explosfve or electronic neutron generators is cone under conputer control using BAS!C, assembly language drivers, and the hardware 1liustrated in F1gure 8. The primary dfferences in testing electronic units as opposed to explosive unt ts is that ascliloscopes are used as a backup on explosive neutron generators, and much more zutonation is used on electronic neutron generators.

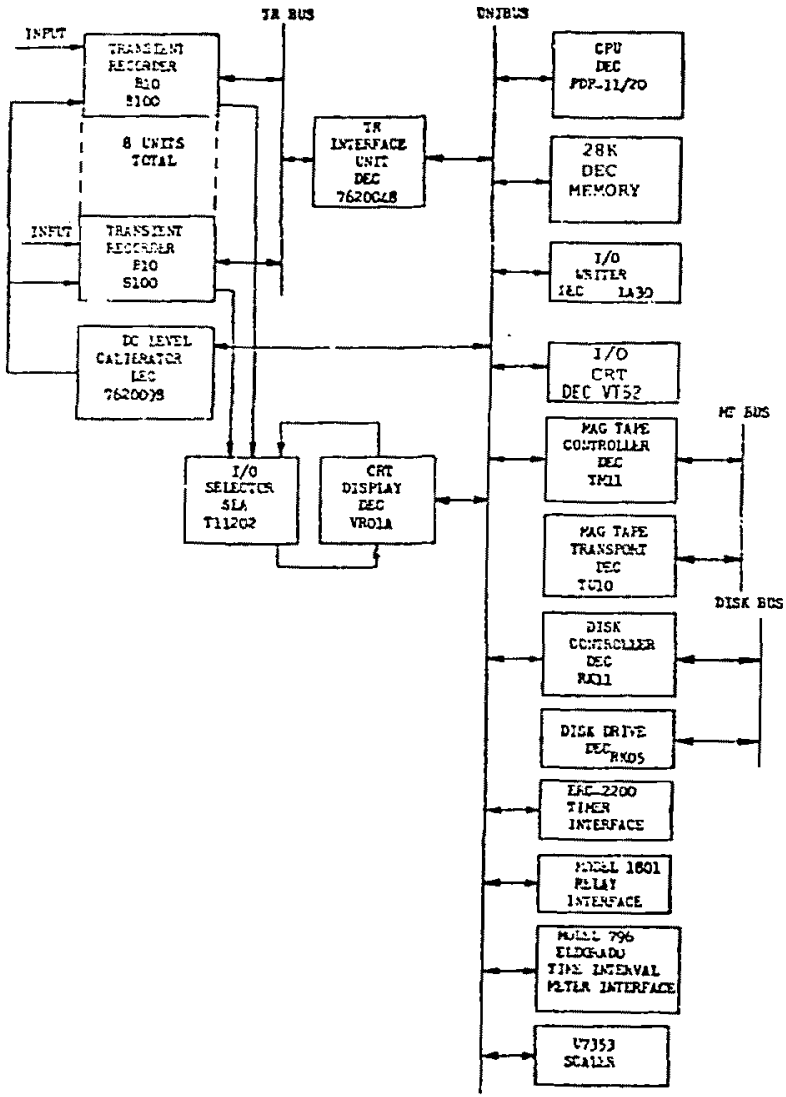

Figure 8. Olgitizer Martware Biock Dlagram 
For eitier type unit, the calibrator is first used to amplitude calibrate the translent recorders and determine TCORR. The calibrator is then used to stmulate the unit to be tested to dry run the system.

A neutron source is used to verify the ne:crum oetector. The source is either - Controllatron or an electronic neutron generator. Since the neutron calibration is obtained from the scaler and the integral of the prompt pulse, the amplitude of the output of the neutron source is not important.

The transfomer assembly. Figure 9, has connactions for the calibrator to convententiy put current through the approprlate trainsformers.
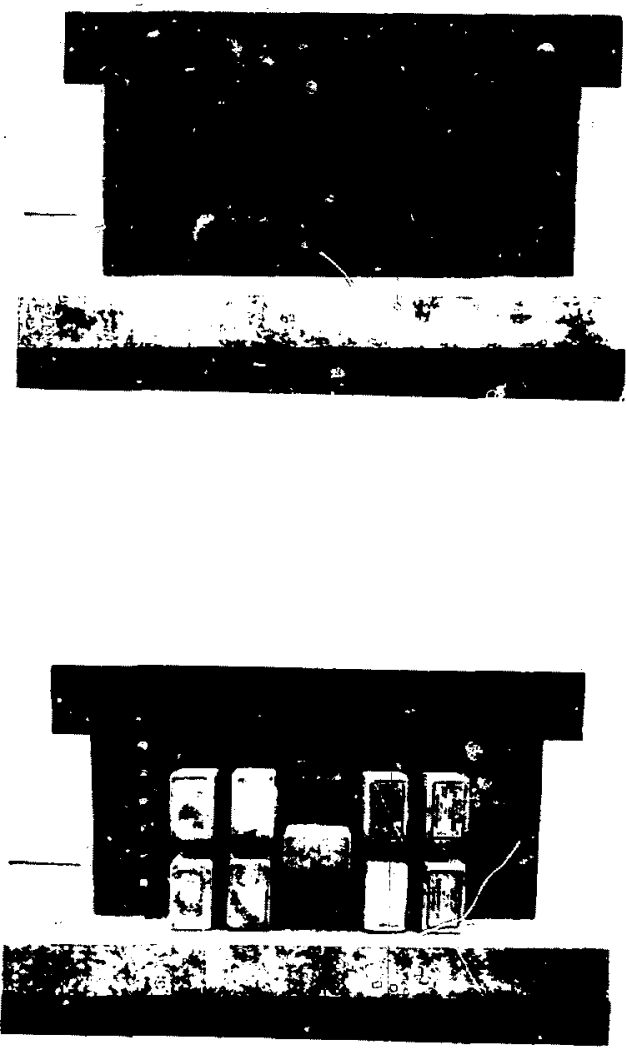

Figure 9. Transformer Assembly 
The computer program reads the amplitude callbration values from the RKO5 disk and compares these values with the amplitudes actually read from the transient recorders, and stores a value which will te used to correct the sensitivites used for ail signals except neutrons. The values from the disk are printed along with the values from the transfent recorder so the computer operator can check for any drastlc discrepancles.

As a final check of the system, including the neutron detector, the timing is changed to carrespond to the time of the neutron generator to $t a$ tested and a neutron waveform is provided by triggeri. the system and the controllatron. eisewhere. (1)

Except for the calibration factors, the system functions close to methods described

\section{SYSTEM VERLFICATION}

The final cileck on the digitizing system was made by digitizing waveforms from the Hodel 100 callorator and measuring the time of the waveforms with an Eldorado Model 796 time interval counter. The waveforms were then placed on the tape in the $\operatorname{CDC} 6600$ library $(1,2)$ and the waveform time-amplitude array printed and plotted under NOS using the Tektronix Model 4051 computer graphics terminal and 463 i plotter.

Table 1 contains the comparison of the time and amplitudes as measured at the caltbrator and as measured from the digitized wayeforms.

Table I. Comparison Between Calibrator Dutput and Digitized Waveforms

\section{Test 1}

\begin{tabular}{lcccc} 
& \multicolumn{2}{c}{ Calibrator } & & \multicolumn{2}{c}{ Digitized Waveforms } \\
\cline { 2 - 3 } & $\frac{\text { Time }}{30.328}$ & $\frac{\text { Amplitude }}{-0}$ & & $\frac{\text { Time }}{\text { Amplitude }}$ \\
SIG 2 & & 2.02 & & \\
SIG 3 & & 1.03 & & -0 \\
SIG 4 & & 2.02 & & 1.045 \\
SIG 5 & & 4.77 & & 2.045
\end{tabular}

Test 2

\begin{tabular}{|c|c|c|c|c|}
\hline & \multicolumn{2}{|c|}{ Calibrator } & \multicolumn{2}{|c|}{ Digitized Waveforils } \\
\hline & Time & Ampli tude & Time & Amplitude \\
\hline & 30.337 & -- & $\overline{30.30}$ & $-m$ \\
\hline SIG 2 & & 2.02 & & 2.03 \\
\hline SIG 3 & & 1.03 & & 1.045 \\
\hline $5: 64$ & & 2.02 & & 2.045 \\
\hline$\$ 165$ & & 4.77 & & $4.79]$ \\
\hline
\end{tabular}


Since tre Biomation Mudel 8100 is operated with a tine increment of $0.02 \mathrm{us}$, its accuracy carrict oe bet:er than $=0.02 \mathrm{is}$. The data fn Table I fndicates that the data is within \pm 2 digfized values or $0.04 \mathrm{ks}$. This agrees with data taken at the test. site dy E. L. Jacoss, Division 2352 .

The amplicude agraement ir. Table I, along with the timing igreement, indicates the systen is operating correctly, without defining ultimate accuracy.

\section{ACCURACY}

The fact that a new system has been implemented naturally leads to questions of accuracy. It is difficult to compare the new methods with the old. since accuracy of the old systen has rever been carefully defined. It can readily bo seen that the new system is more accurate than the old and certainly accurate enough for any presentiy krown applications. From Seciian VII, Table I, the timing accliracy is \pm 0.04 us. Altrough it would ake lot more deta to defend the 0.04 us figure, it seens very safe to say that the systen is within our requirenent of $\pm 0.7 \mathrm{us}$.

The amplitude accuracy of the system using known signals can also be easlly verified from Table 1. Since the reproduction of the waveforms fed into the system is well wtinin the caijuration of the caliorator as scated by Sandia Standards, the amplitude accuraty of the system is the linits set by Standards which is $\pm 5 \%$

Since the digitized neutron sensitivity is determined by the scaler reading and the computer-derived integral of the prompt waveform, the new system should be more accurate than the old since the neutron sensitivity is calculated each time the generator is functioned which compensates for detector drift. However, absolute neutron measurements depend on many factors beyond the scope of this report.

The PUP anasurement depends on both the calibrator and the calibration of the unit PUP. If tne PUP calibration is done at the neutron generator test facility, $E$. L. Jacots' investigation indicates the PUP measurement should be between \pm 5 and \pm 10 . The agreement of the Area II measurements with the predicted output of varistorcontrolled inits indicates the $\pm 5 \%$ is probably close. If the units are calfbrated at GEND. no accuracy can be arrived at when the units are tested in the Area II factlity; however, no serious discrepancy between the measured target voltage of units callorated at GEND and at the Area 11 test factility have been reported by the staff members responsible for the various neutron gennerators.

Dther information on the reproduction of waveforms by the transtent recorders is avallable $(i, 3)$ so it will not be covered here.

It seers that all reasurements, with the possible exception of neutron output, are accurate enough for the measurement of waveforms fram neutron generators and other knowin applications. 


\section{REFERENCES}

1. T. C. Bryant, "Update and Summary of the Division 2351 Neutron Generator Waveform Digitizing and Analysis System (U)." SAND76-0354, January 1977, CRD.

2. T. C. Bryart, "An Overview of the Division 2351 Neutron Generator Test Factilty Waveform Digitizing System (U)." SAND7B-D097, February 1978. unclassifteó.

3. N. A. Botrgeois, Jr., "A Haveform Digitizing System (U)," SAND74-0152, February 1975, unclassified. 
Unilmited Release

Distribution Category UC-37

Otstribution:

Geneiral Electric Company (3)

Neutron Devices Department

P. 0 . Box 11508

St. Petersburg, FL 33733

Attn: R. W. Bruner

W. R. Chamberlain

F. D Thtbideau

Lawrence Liveimore Laboratory

P. 0. Box 808

Liverinore, CA 94550

Attn: D. F. Cruff, $L-125$

L. G. Keller, L-35

Univers: ty of Cal ifornta

Department of Nuclear Engineering

Berkeley, CA 94720

Atin: L. Ruby

Los Alamos Scientific Laboratory (2)

P. 0 . Box 1663

Los Alamos, NM 87544

Attn: L. M. Bayjett, M0O

R. D. Johnson, TD-4

1132 औ. A. Lermon

1415 J. T. Hillman

Attn: $R$ R. Balthaser

2164 J. J. Marron

Attn: R. P. Gullford

2350 J. T. Grissom

2351 R. C. Dougherty (5) (For transmittal to UK)

2351 T. C. Bryant (6)

2351 W. E. Newman

2351 G. E. Rochau

2351 C. $\bar{c}$. Spencer

2352 F. M. Bacon

2352 E. L. Jacobs

2352 R. J. Walko

2353 G. W. MCClure

2354 8. E. Barnaby Attn: M. L. O'Nea?

2355 H. M. Bivens Attn: R. W. Gray

2425 J. R. Yoder

C. A. McKeever

4362 K. D. Hardin

g116 K. A. Mitchel!

8266 E. A. Aas

3141 T. L. Werner

3151 W. L. Garner 